\title{
Two fetuses with Fryns syndrome without diaphragmatic defects
}

\author{
Klaus K Wilgenbus, Rainer Engers, Gerd Crombach, Frank Majewski
}

\begin{abstract}
We report two fetuses with Fryns syndrome including the typical facial appearance and distal limb and lung hypoplasia, but no diaphragmatic hernias. The parents were consanguineous. Characteristic in both cases were the distal limb defects with brachytelephalangism and aplasia of the distal phalanges of the first toe. Since one of the two sibs had severe lung hypoplasia without macroscopic or microscopic defects of the diaphragm, we show that lung hypoplasia can occur independently from diaphragmatic defects in Fryns syndrome.
\end{abstract}

( $(\mathcal{M}$ Med Genet 1994;31:962-964)

In 1979 Fryns et al described a lethal malformation syndrome characterised by "coarse" facies, macrostomia, distal limb defects, pulmonary hypoplasia, and diaphragmatic defects. The spectrum of other less frequent anomalies includes cleft palate/cleft lip, polyhydramnios, cardiac and cerebral malformations, and anomalies of the GI and urogenital tract. ${ }^{2-4}$ To date some 45 cases have been reported including four reports with different chromosomal anomalies and similar symptoms. ${ }^{5-8}$ The autosomal recessive mode of inheritance is now firmly established in view of affected sibs $^{1-3}$ and parental consanguinity. ${ }^{910}$ The prevalence is estimated to be $0 \cdot 7 / 10000$ births in southern France. ${ }^{11}$ The most prevalent congenital anomalies are lung hypoplasia, diaphragmatic hernia, and the characteristic distal limb defects occurring in about $90 \%$ of cases. ${ }^{21}$

We report two fetuses with typical ma- nifestations of Fryns syndrome such as lung hypoplasia, characteristic facial appearance, distal limb and gastrointestinal abnormalities, but no obvious diaphragmatic defects.

\section{Case reports}

CASE 1

The parents of this patient were first cousins of Turkish descent. They already had one healthy daughter. This pregnancy proceeded normally until 17 weeks of gestation when ultrasound scan showed severe fetal hydrops. Amniotic fluid volume was normal. The pregnancy was terminated and a male fetus weighing $241 \mathrm{~g}$ with a crown-heel length of $16 \mathrm{~cm}$ and a crownrump length of $12.5 \mathrm{~cm}$ (compatible with 17 weeks' gestation) was delivered. Other than fetal hydrops, nuchal hygroma, and retrogenia (fig 1A), marked hypoplasia of the terminal phalanges of all fingers and toes 2 to 4 was present. The terminal phalanges of toes 1 and 5 were absent (fig 1B). Necropsy showed malfixation of the intestines, an imperforate anus, and a single umbilical artery. Neither lung hypoplasia nor a diaphragmatic hernia was present. The karyotype was $46, \mathrm{XY}$.

\section{CASE 2}

This pregnancy, the fourth for the mother of case 1, proceeded normally until 19 weeks of gestation when an ultrasound scan showed nuchal hygroma and massive pleural effusions. Neither a diaphragmatic hernia nor other defects were observed and amniotic fluid volume was normal. The pregnancy was terminated at 20 weeks of gestation and a female fetus weighing $308 \mathrm{~g}$ was delivered. The crown-heel length

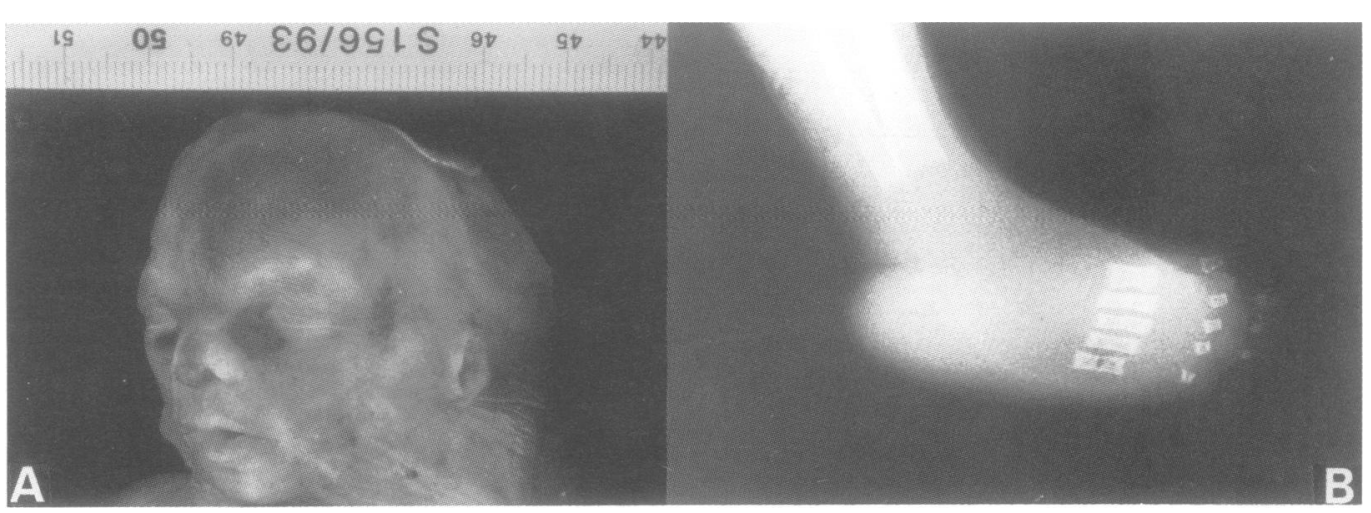

Figure 1 Case 1. (A) Craniofacial appearance with nuchal hygroma and retrognathia. (B) Radiograph of left foot. Note aplasia of terminal phalanges of toes 1 and 4. 


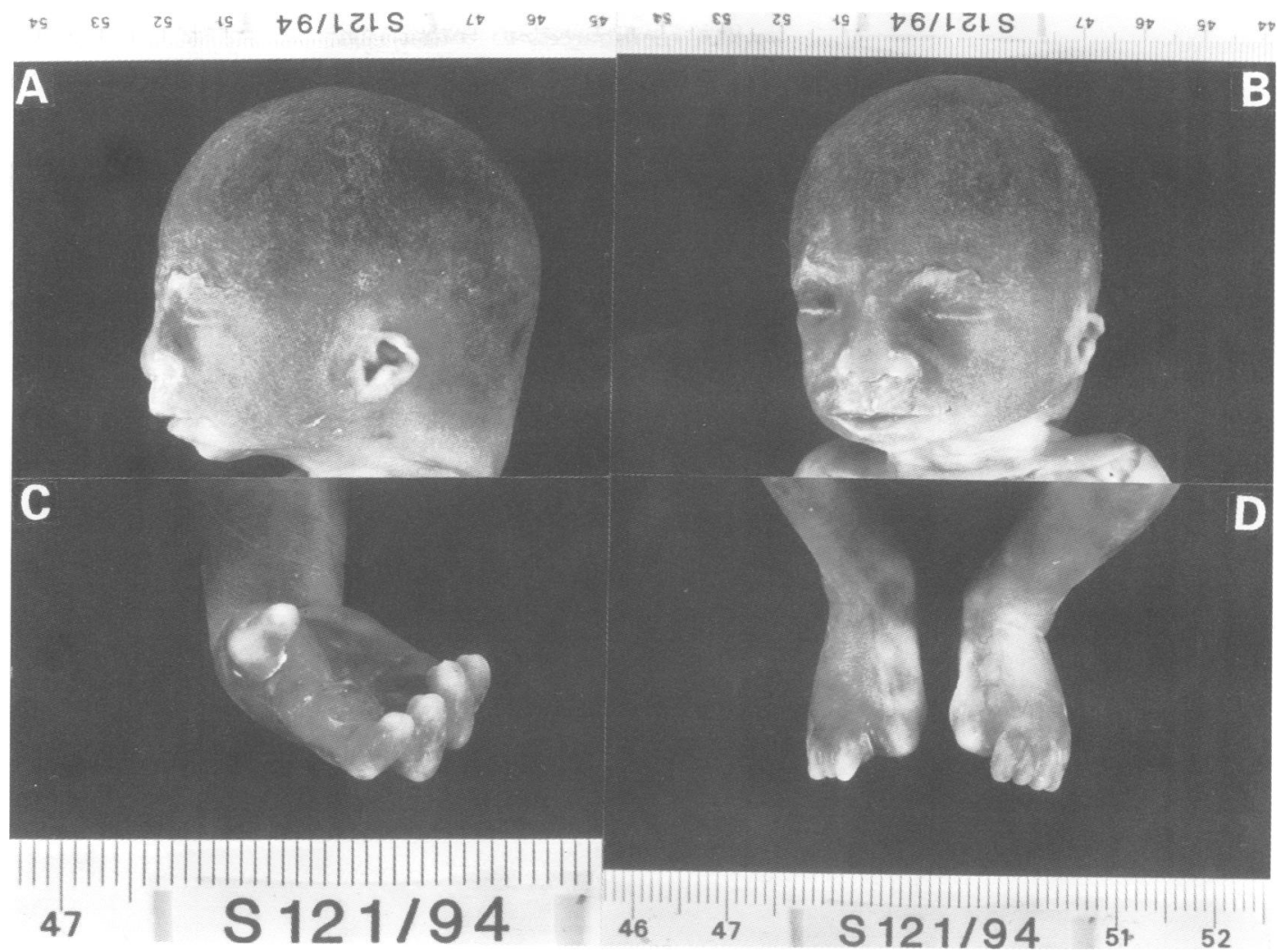

Figure 2 Case 2. (A) Lateral view of face showing dysmorphic, low set ears and severe retrognathia. (B) Frontal view showing macrostomia and broad nasal bridge. (C) Right hand. Note distal digital hypoplasia and aplasia of all nails.
(D) Feet with bilateral aplasia of toe 1 and absent nails.

was $26 \mathrm{~cm}$ and the crown-rump length was $19 \mathrm{~cm}$ (compatible with 20 weeks' gestation). Craniofacial dysmorphism consisted of macrostomia, broad nasal bridge, retrogenia and low set, dysmorphic ears (fig 2A,B). The hands and feet showed distal hypoplasia with absent nails on all fingers and toes and bilateral aplasia of the distal phalanges of the first toe (fig $2 \mathrm{C}$, D). Necropsy showed bilateral hypolastic lungs (weight $2.9 \mathrm{~g}$, expected $7.2 \mathrm{~g}$ ) and massive pleural effusions. The intact diaphragm was in the normal position and microscopic examination of several biopsies showed no muscle hypoplasia when compared to an age matched control fetus. No other visceral malformations were observed on careful macroscopic and microscopic inspection. The brain and eyes were normal. Chromosome analysis on amniotic cells and chorionic villi showed a normal karyotype $46, \mathrm{XX}$.

\section{Discussion}

We present here two fetuses with Fryns syndrome and consanguineous parents. The observed phenotypic changes include fetal hydrops, nuchal oedema, facial and distal limb abnormalities, lung hypoplasia, and intestinal malformations. Considering the broad phenotypic heterogeneity of Fryns syndrome, our two sibs showed very similar findings. Characteristic in both cases were the distal limb defects with brachytelephalangism and aplasia of the distal phalanges of the first toe (figs $1 \mathrm{~B}$ and $2 \mathrm{C}, \mathrm{D})$. Case 1 also showed malformation of the gastrointestinal tract including mal- fixation and an imperforate anus. Whereas intestinal malfixation is commonly observed in Fryns syndrome, anal atresia or an imperforate anus have been only described in a subset of cases with this syndrome. ${ }^{3}$

In contrast to most other reported cases of Fryns syndrome, our cases did not show any evidence of diaphragmatic hernias. Diaphragmatic hernia, usually a left posterolateral defect, was observed in all but a few published cases of Fryns syndrome. Two patients were reported to have high diaphragms, possibly reflecting muscle hypoplasia, ${ }^{10} 12$ and Stratton et $a l^{13}$ reported one female patient with bilateral posterior eventration. Willems et $a l^{14}$ reported a patient with Fryns syndrome with a thin and hypoplastic but otherwise intact diaphragm. Two further patients, patient 3 reported by Bamford $e t a l^{\beta}$ and another boy (Cunniff et $a l^{4}{ }^{4}$ case 4), apparently had normal diaphragms, but these patients are the only ones known to have survived the neonatal period. Since these two patients did not show the typical phenotype of Fryns syndrome it could be argued that these children were either very mildly affected or that they did not have Fryns syndrome. Fryns et al proposed that diaphragmatic defects may be secondary to lung hypoplasia because the pleuroperitoneal folds from which the posterolateral parts of the diaphragm develop depend upon normal lung growth. Alternatively, Willems et al $^{14}$ suggested that diaphragmatic anomalies are responsible for lung hypoplasia.

Both our fetuses showed intact diaphragms in a normal position. Histological examination of the diaphragm of case 2 showed no ab- 
normalities when compared to other age matched controls. We conclude that diaphragmatic defects and lung hypoplasia are not as tightly linked to each other as previously proposed. A possible explanation for the lung hypoplasia in case 2 might have been the fetal hydrops and pleural effusion.

1 Fryns JP, Moerman F, Gooddeeris P, Bossuyt C, Van den Berghe $H$. A new lethal syndrome with cloudy corneae, diaphragmatic defects and distal limb deformities. Hum Genet 1979;50:65-70.

2 Moerman P, Fryns JP, Vandenberghe K, Devlieger $H$ Lauweryns JM. The syndrome of diaphragmatic hernia, abnormal face and distal limb anomalies (Fryns syndrome) report of two sibs with further delineation of the multiple congenital anomalies. Am $\mathcal{F}$ Med Genet 1988;31:805-14.

3 Bamford JS, Leonard CO, Chodirker BN, et al. Congenital diaphragmatic hernia, coarse facies, and acral hypoplasia: Fryns syndrome. Am f Med Genet 1989;32:93-9.

4 Cunniff C, Jones KL, Saal HM, Stern HJ. Fryns syndrome: an autosomal recessive disorder associated with craniofacial an aulies, diaphal Pediatrics 1990;85:499-504.
5 Clark RD, Fenner-Gonzales M. Apparent Fryns syndrome in a boy with a tandem duplication of 1q24-31.2. Am $7 \mathrm{Med}$ Genet 1989;34:422-6.

6 deJong G, Roussow RA, Retief AE. Ring chromosome 15 in a patient with features of Fryns syndrome. 7 Med Genet 1989;26:469-70.

7 Krassikoff N, Sekhon GS. Terminal deletion of $6 \mathrm{q}$ and Fryns syndrome: a microdeletion/syndrome pair? Am $\mathcal{f} M e d$ Genet 1990;36:363-4.

8 Schneider M, Suhr L, Hawkins $H$, Hughes $M$. A second case of Fryns syndrome associated with a duplication of $1 \mathrm{q} 22-$ of Fryns syndrome associated with a duplication of 1 q $22-$ 32; a karyotype associatio

9 Meinecke P, Fryns JP. The Fryns syndrome: diaphragmatic defects, craniofacial dysmorphism, and distal hypoplasia. Clin Genet 1985;28:516-20.

10 Schwyzer U, Briner J, Schinzel A. Fryns syndrome in a girl born to consanguineous parents. Acta Paediatr Scand 1987; 76:167-71.

11 Ayme S, Julien C. Gambarelli D, et al Fryns syndrome: report on 8 new cases. Clin Genet 1989;35:191-201.

12 Lubinsky M, Severn C, Rapoport JM. Fryns syndrome: a variable multiple congenital anomaly (MCA) syndrome. Am 7 Med Genet 1983;14:461-6.

13 Stratton RF, Young RS, Heiman HS, Carter JM. Fryns syndrome. Am $\mathcal{Y}$ Med Genet 1993;45:562-4.

14 Willems PJ, Keersmaekers GHA, Dom KE, et al. Fryns syndrome without diaphragmatic hernia. Am $\mathcal{f}$ Med Genet 1991;41:255-7. 